\title{
Profil Pelepasan Andrografolid Granul Kombinasi Ekstrak Terpurifikasi Herba Pegagan (Centeella Asiatica) Dan Sambiloto (Andrographis Paniculata)
}

\author{
Lina Widiyastuti ${ }^{1 *} \&$ Akhmad Kharis Nugroho ${ }^{2}$ \\ ${ }^{1}$ Fakultas Farmasi Universitas Ahmad Dahlan Yogyakarta \\ ${ }^{2}$ Fakultas Farmasi Universitas Gadjah Mada Yogyakarta \\ *Corresponding author: lina.widiy1979@gmail.com
}

\begin{abstract}
Background: Andrografolid is a water-soluble compound, the determination of the amount and profile of the andrographolide release of the dosage form is necessary. Objective: This research is aimed to determine the amount and profile of andrographolide release of granules combination purified extract of pegagan and sambiloto herbs. This study was conducted to ensure that excipient does not bind the active ingredient. Methods: The release test was conducted through a dissolution test using acetat buffer $\mathrm{pH}$ 4,5 media. The dissolution result of granule was determined using TLC-Densitometry. Results: The dissolution effisiency $\left(D E_{60}\right)$ result was $75,00 \% \pm 1,33$. The dissolution profiles were determined by nonlinear regression approach zero order, first order, Higuchi, Hixon Crowell, and KorsmeyerPeppas. The mechanism determining the dissolution profile of andrographolide release was seen visually from the suitability of the result of solver prediction $\left(Q_{\text {prediction }}\right)$ and experiment $\left(Q_{\text {observation }}\right)$ with identity line. The curve of a model which closer to identity line was the description of andrographolide release mechanism which was formed with the approach. The curve with Korsmeyer Peppas approach was closer to the identity line than the other four approach model. Based on nonlinear regression calculation, the release of andrographolide was controlled by a matrix diffusion mechanism, it means that andrographolide release of granules was occured because of the erosion of the outer layers which was caused by the quickly hydrated Avicel PH 101. By using Kormeyer Peppas equation, mechanism of drug release follows the Fick diffusion law with the value $n=0.320$ (<0,45). Conclusions: The amount and profile of andrographolide released from granule are the research finding that can be applied as a reference to determine the amount of extract used in a formulation.
\end{abstract}

Keywords: andrographolide, realease profile, krosmeyer-peppas

\begin{abstract}
Abstrak
Pendahuluan: Andrografolid merupakan senyawa yang sukar larut dalam air, penentuan jumlah dan profil pelepasan andrografolid dari bentuk sediaan perlu dilakukan. Tujuan: Penelitian ini dilakukan untuk menentukan jumlah dan profil andrografolid yang dilepaskan dari formula granul kombinasi ekstrak terpurifikasi herba pegagan dan herba sambiloto. Hal tersebut untuk memastikan eksipien tidak mengikat zat aktif. Metode: Uji pelepasan dilakukan dengan melakukan uji disolusi menggunakan media dapar asetat $\mathrm{pH}$ 4,5. Hasil disolusi granul kombinasi ekstrak terpurifikasi herba pegagan dan herba sambiloto ditentukan menggunakan KLTdensitometri. Hasil: Hasil perhitungan efisiensi disolusi $\left(\mathrm{ED}_{60}\right)$ sebesar $75,00 \% \pm 1,33$. Profil disolusi ditentukan dengan regresi nonlinear dengan pendekatan orde nol, orde 1, Higuchi, Hixon Crowell dan Korsmeyer Peppas. Mekanisme penentuan profil disolusi dari pelepasanan andrografolid dilihat secara visual dari kesesuaian hasil prediksi solver $\left(\mathrm{Q}_{\text {Prediksi }}\right)$ dan hasil percobaan $\left(\mathrm{Q}_{\text {observasi }}\right)$ dengan melihat garis identitas. Kurva dari suatu model yang mendekati garis identitas merupakan gambaran mekanisme pelepasan andrografolid yang dibentuk dengan pendekatan tersebut. Kurva dengan pendekatan Korsmeyer Peppas terlihat lebih dekat dengan garis identitas bila dibandingkan dengan 4 model pendekatan yang lain. Berdasarkan perhitungan regresi nonlinear, pelepasan andrografolid dikontrol dengan mekanisme difusi matriks, yang berarti pelepasan andrografolid dari granul terjadi karena adanya pengikisan lapisan terluar karena Avicel PH 101 terhidrasi dengan cepat. Dengan menggunakan persamaan Korsmeyer-Peppas mekanisme pelepasan andrografolid mengikuti hukum difusi Fick dengan nilai $\mathrm{n}=0,320(<0,45)$. Kesimpulan: Jumlah dan profil pelepasan andrografolid dari granul adalah hasil penelitian yang dapat dijadikan suatu referensi untuk menentukan jumlah ekstrak yang dipakai dalam formulasi.
\end{abstract}

Kata kunci: andrografolid, profil pelepasan, korsmeyer-peppas

\section{PENDAHULUAN}

Pelepasan zat aktif memberikan gambaran zat aktif lepas meninggalkan bentuk sediaan dan selanjutnya akan mengalami absorbsi, distribusi, metabolisme dan eksresi. Hal ini merupakan suatu keniscayaan untuk suatu zat aktif dapat memberikan efek farmakologis yang diharapkan. Pemilihan eksipien yang tepat merupakan kunci dari problem pelepasan. Eksipien hanya akan mengantarkan zat aktif sampai tempat terjadinya pelepasan zat aktif, tanpa harus 
mempengaruhi zat aktif sehingga dapat terlepas optimal (Anwar, 2012).

Kelarutan zat aktif merupakan faktor penting agar obat dapat diabsorpsi. Selanjutnya zat aktif akan larut dalam medium sebagai fungsi waktu. Jumlah zat aktif yang terlarut dapat disampaikan dengan beberapa metode diantaranya metode klasik $\left(\mathrm{C}_{20}\right.$ atau $\left.\mathrm{T}_{20}\right)$ maupundisolusi efisiensi (DE). Metode DE digunakan untuk menyampaikan hasil pengamatan kecepatan disolusi obat karena lebih bisa menggambarkan keseluruhan proses disolusi (Fudholi, 2013).

Metode nonlinier atau linierisasi kurva dapat juga digunakan untuk mengungkapkan hasil dissolusi. Pada metode ini dapat digunakan pendekatan model Higuci, Krosmeyer-Peppas, Hixon-Crowell, Weibull, First order dan Zero order.

\section{BAHAN DAN METODE \\ Bahan}

Bahan yang digunakan dalam penelitian ini adalah andrografolid p.a (sigma), kloroform p.a (Merck), etanol p.a (Merck), metanol p.a (Merck), $n$-butanol p.a (Merck), asam asetat p.a (Merck), lempeng silika gel $60 \mathrm{~F}_{254}$, natrium lauril sulfat (Merck), etil asetat (Merck), kertas saring, dan pereaksi LiebermanBurchard.

Alat

Alat yang digunakan dalam penelitian ini adalah KLT dengan fase diam lempeng silika gel $60 \mathrm{~F}_{254}$, Densitometer (Camag TLC Scanner 3), Dissolution tester (Erweka DT 720).

\section{Metode}

Ditimbang granul seberat $738 \mathrm{mg}$ dimasukkan dalam medium disolusi yaitu 500,0 mL larutan dapar asetat $\mathrm{pH} 4,5$ yang ditambah dengan larutan Sodium Lauryl Sulphate (SLS) 0,1 M sebanyak $5 \mathrm{~mL}$. Keranjang diputar dengan kecepatan $50 \mathrm{rpm}$ dan jarak antara ujung keranjang dengan dasar labu 2,0 $\pm 0,2 \mathrm{~cm}$. Diambil sampel medium pada waktu 0, 5, 10, 15, 30 dan 60 menit sebanyak 5,0 mL. Dimasukkan medium sebanyak 5,0 $\mathrm{mL}$ untuk mengganti volume sampel dengan suhu yang sama yaitu $37 \pm 0,5^{\circ} \mathrm{C}$. $5 \mathrm{~mL}$ sampel dimasukkan dalam labu takar $10 \mathrm{~mL}$, ditambah dengan $5 \mathrm{~mL}$ etil asetat, divortek 3 menit, didiamkan hingga memisah 2 fraksi, diambil fraksi etil asetat diuapkan pada suhu $50^{\circ} \mathrm{C}$ sampai kering kemudian dilarutkan kembali dengan etil asetat $1 \mathrm{~mL}$ untuk penotolan. Filtrat yang diperoleh ditotolkan sebanyak $30 \mu \mathrm{L}$ pada silika gel $60 \mathrm{~F}_{254}$ dan dielusi menggunakan fase gerak $\mathrm{CHCL}_{3}$ : $\mathrm{MeOH}$ (9:1) (Kementerian Kesehatan, 2009). Dilakukan perhitungan jumlah zat aktif yang terlepas.

\section{HASIL DAN PEMBAHASAN}

Granul kombinasi ekstrak terpurifikasi herba pegagan dan sambiloto mengandung asiatikosida dan andrografolid sebagai senyawa aktifnya. Uji pelepasan zat aktif granul lebih difokuskan pada kandungan andrografolid yang terdapat dalam granul karena andrografolid merupakan zat yang kelarutannya kecil dalam air. Disolusi merupakan tahapan penting yang menentukan bioavailabilitas, maka uji disolusi andrografolid pada granul kombinasi ekstrak terpurifikasi herba pegagan dan herba sambiloto merupakan parameter yang tepat. Uji disolusi memberikan informasi tentang kecepatan disolusi, jumlah obat yang terlepas tiap-tiap waktu dan disolusi efisiensi (DE) serta mekanisme pelepasan obat dari sediaan.

Hasil disolusi granul kombinasi ekstrak terpurifikasi herba pegagan dan sambiloto terlihat pada hasil kromatografi lapis tipis. Sampel memberikan hasil yang sama dengan $\mathrm{R}_{\mathrm{f}}$ andrografolid standar (Gambar 1).

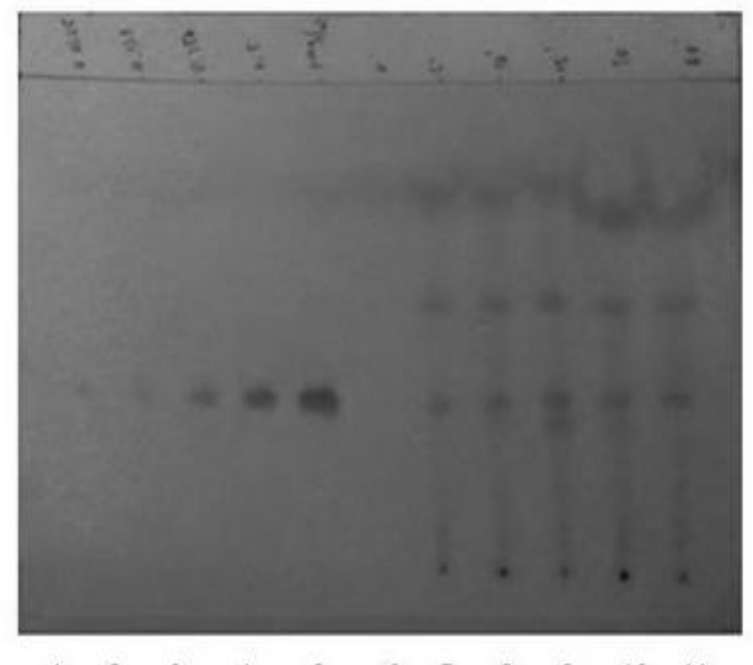

$\begin{array}{lllllllllll}1 & 2 & 3 & 4 & 5 & 6 & 7 & 8 & 9 & 10 & 11\end{array}$

Gambar 1. Profil KLT uji kualitatif dalam media disolusi, berurutan kiri ke kanan (1), (2), (3), (4), (5) standar andrografolid konsentrasi 0,063; 0,125; 0,250; 0,500 dan $1 \mathrm{mg} / \mathrm{mL},(6),(7),(8),(9),(10),(11)$ sampel pada waktu ke- $0,5,10,15,30$ dan 60 menit, dengan fase gerak kloroform:metanol = 9:1, fase diam silika gel $60 \mathrm{~F}_{254}$, jarak elusi $8 \mathrm{~cm}$, penampak bercak sinar UV 254.

Andrografolid standar dibuat seri baku standar dengan konsentrasi $1 ; 0,5 ; 0,25 ; 0,125$ dan $0,0625 \mathrm{mg} / \mathrm{mL}$ dengan penotolan sebanyak $5 \mu \mathrm{L}$. Hasil penetapan kurva baku dilihat pada Gambar 2 .

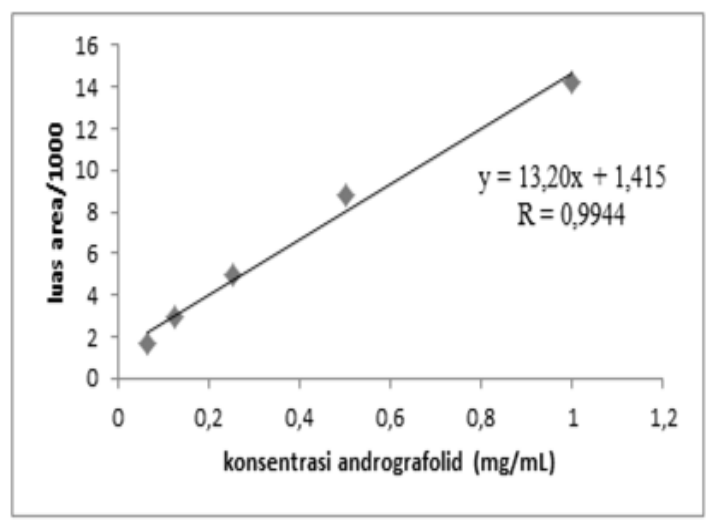

Gambar 2. Kurva baku konsentrasi vs luas area andrografolid 
Tabel 1. Bobot kumulatif andrografolid (mg) sebagai fungsi waktu (menit)

\begin{tabular}{cc}
\hline Waktu (menit) & Bobot kumulatif andrografolid (mg) \\
\hline 0 & 0,00 \\
5 & 4,21 \\
10 & 4,60 \\
15 & 5,68 \\
30 & 7,33 \\
60 & 8,75 \\
\hline
\end{tabular}

Persamaan kurva baku yang diperoleh, digunakan untuk menetapkan jumlah andrografolid dalam sampel. Diperoleh hasil yang disajikan pada Tabel 1. Data yang tersaji pada Tabel 1 digunakan untuk menghitung disolusion effisiensi (DE) andrografolid. Disolusion effisiensi didefinisikan sebagai area under the dissolution curve (AUC) terhadap waktu, dihitung sebagai persentase area terhadap $100 \%$ disolusi pada waktu yang sama (Gambar 3). Hasil perhitungan data yang disajikan Tabel 1 diperoleh $\mathrm{DE}_{60}$ sebesar 75,00\% $\pm 1,33$, yang berarti bahwa selama 60 menit $75 \%$ andrografolid terlepas .

Mekanisme pelepasan andrografolid dari sediaan granul dapat diketahui dengan perhitungan regresi linear hubungan bobot kumulatif andrografolid yang terlepas terhadap waktu (Gambar 3) dan perhitungan regresi nonlinear dengan pendekatan orde nol, orde 1, Higuchi, Hixon Crowell dan Korsmeyer Peppas (Costa $\&$ Lobo, 2001).

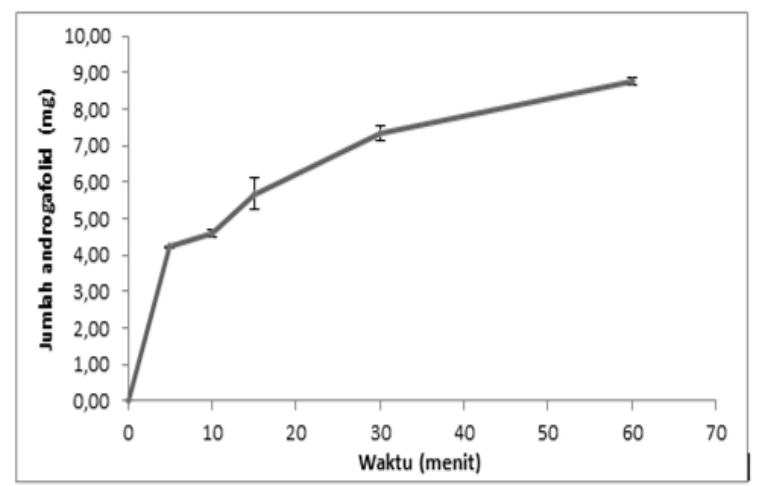

Gambar 3. Kurva hubungan bobot kumulatif andrografolid vs waktu

Profil disolusi dengan regresi linear tidak memperlihatkan linearitas sehingga tidak dapat ditentukan mekanisme pelepasan dengan tepat, maka dilakukan cara kedua yaitu perhitungan regresi nonlinear dengan pendekatan orde nol, orde 1, Higuchi, Hixon Crowell dan Korsmeyer Peppas.

Penentuan mekanisme dilihat secara visual kesesuaian bobot kumulatif andrografolid yang terlepas hasil prediksi solver $\left(\mathrm{Q}_{\text {prediksi }}\right)$ dan hasil percobaan $\left(\mathrm{Q}_{\text {observasi }}\right)$ dengan garis identitas. Kurva dari suatu model yang mendekati garis identitas merupakan gambaran mekanisme pelepasan andrografolid yang dibentuk dengan pendekatan tersebut. Kurva dengan pendekatan Korsmeyer Peppas terlihat dekat dengan garis identitas bila dibandingkan dengan 4 model pendekatan yang lain (Gambar 4).

Gambar 5 merupakan curve fitting hasil disolusi yang menjelaskan lebih lanjut mekanisme pelepasan andrografolid dengan $\mathrm{Q}_{\text {observasi }}$ sesuai dengan kurva prediksi $\left(\mathrm{Q}_{\text {prediksi }}\right)$ yang dibangun model Korsmeyer Peppas.

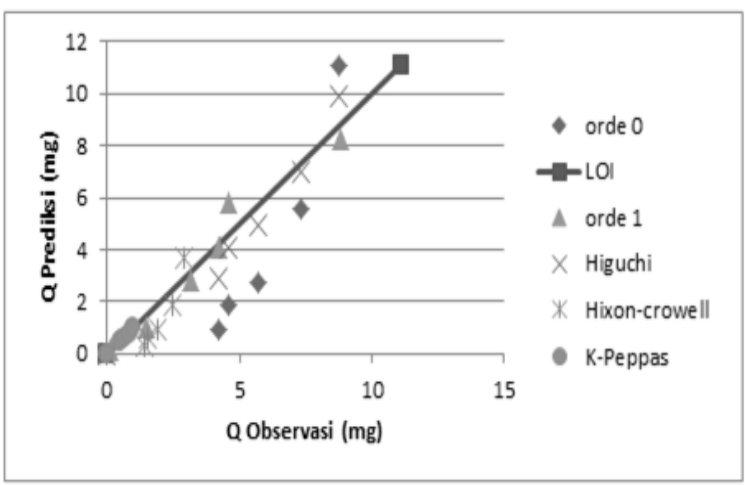

Gambar 4. Kurva goodness of fit

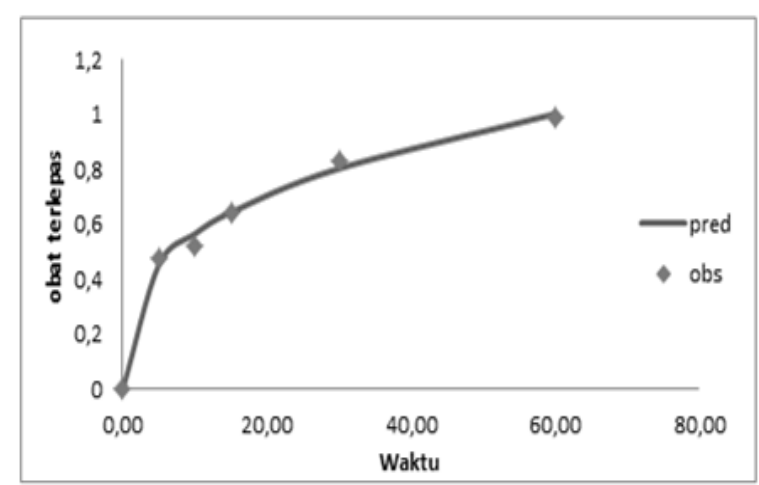

Gambar 5. Kurva fitting pendekatan Korsmeyer Peppas

\section{KESIMPULAN}

Pelepasan andrografolid dikontrol dengan mekanisme difusi matriks berdasarkan perhitungan regresi nonlinear, artinya pelepasan andrografolid dari granul terjadi karena adanya pengikisan lapisan terluar karena Avicel PH 101 terhidrasi dengan cepat. Dengan menggunakan persamaan Krosmeyer-Peppas mekanisme pelepasan obat ditentukan dengan nilai $\mathrm{n}$. 
Jika nilai $\mathrm{n}=<0,45$ pelepasan obat mengikuti hukum difusi Fick dan jika nilai $\mathrm{n}=0,45-0,89$ maka mekanisme pelepasan obat tidak mengikuti hukum Fick, apabila nilai $\mathrm{n}$ lebih besar dari 0,89 maka mekanisme pelepasan mengikuti kinetika orde 0 (Dash dkk., 2010). Granul kombinasi ekstrak terpurifikasi herba pegagan dan sambiloto dengan nilai $\mathrm{n}=0,320 \quad(<0,45)$ mengindikasikan mekanisme pelepasannya mengikuti hukum difusi Fick (Shoaib dkk., 2006). Menurut Fick laju disolusi senyawa padat ditentukan oleh laju disolusi suatu lapisan tipis dari larutan yang terbentuk disekeliling zat padat. Obat yang terlarut dalam larutan jenuh berdifusi kedalam pelarut dari daerah konsentrasi tinggi ke daerah dengan konsentrasi obat rendah.

\section{UCAPAN TERIMA KASIH}

Terima kasih penulis ucapkan kepada semua pihak yang telah memberikan kontribusi selama pelaksanaan penelitian dan sampai publikasi ini. Terimakasih kepada laboran laboratorium Kimia Farmasi Universitas Ahmad Dahlan Yogyakarta yang telah membantu teknis penelitian.

\section{DAFTAR PUSTAKA}

Anwar, E. (2012). Eksipien Dalam Sediaan Farmasi. Jakarta: Dian Rakyat.

Costa, P. \& Lobo, J.M.S. (2001). Modeling and Comparation of Dissolution Profiles. European Journal of Pharmaceutical Sciences; 13; 123133.

Dash, S., Chowdhury, P., Murthy, P.N. \& Nath, L. (2010). Kinetic Modeling on Drug Release from Controlled Drug Delivery System. Acta Poloniae Pharmaceutican Drug Research; 67(3); 217-223.

Fudholi, A. (2013). Disolusi dan Pelepasan Obat in Vitro.Yogyakarta: Pustaka Pelajar.

Kementerian Kesehatan. (2009). Farmakope Herbal Indonesia. Jakarta: Kementerian Kesehatan Republik Indonesia.

Shoaib, M.H., Tazeen, J. \& Merchant, H.A. (2006). Evaluation of Drug Release Kinetic from Ibuprofen Matrix Tablets Using HPMC. Pakistan Pharmaceutical Journal Sciences; 19 (2); 119-124. 